\title{
FEASIBILITY OF USING VANADIUM REDOX FLOW BATTERY AS ENERGY STORAGE IN SOLAR CHIMNEY POWER PLANTS
}

\author{
DR. KAMAL KISHORE PATHAK
}

Department of Mechanical Engineering, Government Polytechnic Sheikhpura, Bihar

\begin{abstract}
This paper presents the basics of utilization of vanadium redox flow battery as energy storage in solar chimney plants. The sole intent of this research is to use renewable source of solar energy so as to reduce harmful environmental effects created by conventional fuels. Moreover, feasibility for VRFB as energy storage and the reliability of the combined system is also presented. Overall, an efficient \& eco-friendly system has been discovered utilizing solar energy. KEYWORDS: Renewable Energy, Solar Chimney Plants, Vanadium Redox Flow Battery
\end{abstract}

Received: Jun 06, 2020; Accepted: Jun 26, 2020; Published: Aug 25, 2020; Paper Id.: IJMPERDJUN2020882

\section{INTRODUCTION}

The recent reports of IEA (International Energy Agency) [IEA2019] [1] indicate a rise of 2.3\% in the worldwide energy demand, which results in $1.7 \%$ growth in emissions of $\mathrm{CO}_{2}$. Unfortunately, most of the present energy demand is being met by reserves of fossil fuels (coal, natural gas, and oil) that cause a negative impact on the environment by emitting various greenhouse gases and other pollutants. At the same instant, the limited reserves of fossil fuels are continuously diminishing and are expected to get depleted within next 60-80 years. All these issues accelerate the need for energy production from renewable resources (for example solar energy, wind energy, geothermal energy, etc.), which leads to clean electricity generation without emission of greenhouse gas (GHG). One of the recent areas of research for them is the applicability of solar energy in solar chimney. Thus several researches have been done on solar chimney power plant. In solar chimney power plant, the sun is the main source of energy that can be utilized for producing energy. These kind of solar powered vehicles are not very common in India, and still researches have been going on in the same direction [2][3][4]. Although these plants have various advantages such as they have zero emissions thus eco-friendly in nature, no fuel costs, and it make significant contributions to the energy requirements of countries with abundance of desert land, such as Africa, and Asia etc., however, certain limitations still persists such as energy storage, design challenges and poor practicability. Dealing with all these limitations is necessary for making solar chimney plant globally available. Both experimental as well as modeling work are going on with full pace to developed this system. Taking a step forward, this paper mainly deals with the energy storage of the solar chimney plants. In this paper we will firstly take a glimpse of main components of the system, working of the system, feasibility of vanadium redox flow batteries as energy storage and the creditability of this system for making itself globally available. Figure 1 shows the working of solar chimney power plants. 


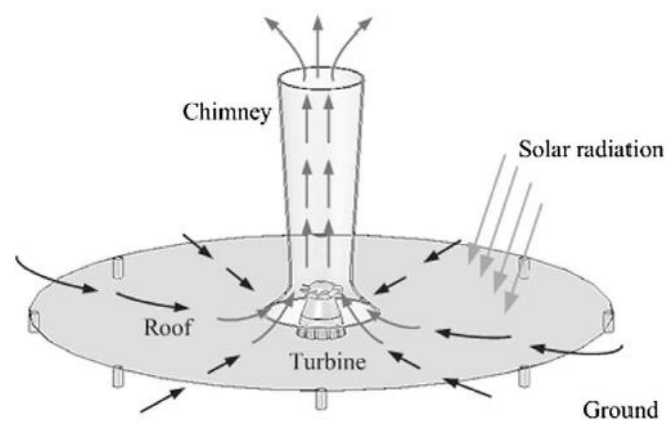

Figure 1: Working of Solar Chimney Power Plants [2].

\section{BASICS OF SOLAR CHIMNEY POWER PLANTS}

Figure 2 shows the overview of components of solar chimney powerplants. The main source of energy for the system is the solar radiations. The solar energy is captured by the collector roofs and then it strikes the earth surface, which further heats the surrounding airs. The heated air beneath the collector flows upwards towards the chimney to herd the turbines. The main components of a solar powered car are as follows: the chimney, the collector, the turbine \& the energy storage.

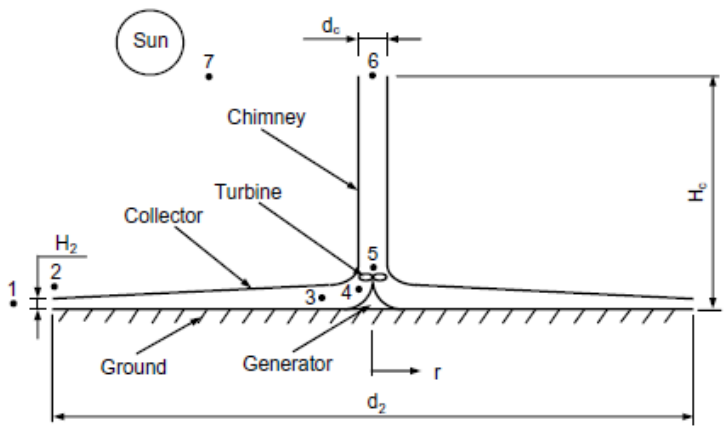

Figure 2: Main Components of Solar Chimney Power Plants.

\section{VANADIUM REDOX FLOW BATTERY AS AN ENERGY STORAGE}

The solar chimney powerplants however are limited by the random distribution and intermittency of the solar radiations. An efficient energy storage system is therefore needed for proper accumulation, transmission and distribution of energy generated from Sun. Compressed air energy depository, pumped hydro energy depository, and flywheel energy depository are some of the energy storage technologies being used nowadays. Electrochemical energy storage devices (ESS) are best suitable among these technologies owing to its fast response time, high energy efficiency, and low standby losses. One of the propitious technology among all ESS devices (for e.g, Fuel cells, batteries and redox batteries, etc.,) is vanadium redox flow battery (VRFB). The potential of vanadium to present in four discrete oxidation conditions in the solution gives vanadium redox flow batteries an advantage over the other redox flow batteries [5][6][7]. The success of this technology also gives credence to some of its other idiosyncratic characteristics, e.g,

- High energy efficiencies,

- Long discharge times, 
- Minimum waste disposal as the use of the same element vanadium in its four oxidizing states avoid problems related to cross-contamination,

- Capability of fully getting discharged without misusing the battery, and

- Minimum environmental effect during production and disposal as compared to other electrochemical systems that utilize heavy metals like cadmium, lead, zinc and nickel

Another important characteristic of the VRFBs is their decoupled energy \& power densities. With this feature, VRFBs can be easily distinguished from other conventional batteries like lead-acid battery and lithium-ion battery.

The energy generated from the solar chimney plants is converted to electrical energy. The generated electrical energy is supplied to the batteries to charge them $\&$ then can be further used to run motor when required. Initially, the batteries are fully charged by the external source $\&$ afterwards they are charged by the panels. This resulted in completing the batteries charging-discharging cycle.

\section{WORKING OF VANADIUM REDOX FLOW BATTERY}

Vanadium redox flow batteries are electrochemical devices which convert the chemical energy of the electrolytes into electric current and vice versa. It is a large stationary electricity storage systems with many potential applications such as, for providing uninterruptible power supply, peak shaving, load leveling, and for emergency backups. The first VRFB was developed in 1980 by Maria Skylas- Kajacos \& co-workers at the North South Wales University in Australia. Figure3 depicts a schematic of VRFB. It consists of two electrodes (termed as positive and negative electrode), a separator, two current collectors, two electrolyte depositories, $\&$ two peristaltic pumps. The electrodes which are typically made up of graphite or carbon felt materials provide active sites for the electrochemical reactions. The electrolytes in both tanks contain vanadium salts, i.e, $\mathrm{V}^{+2}$ and $\mathrm{V}^{+3}$ in the negative electrode and $\mathrm{V}^{+4}$ and $\mathrm{V}^{+5}$ in positive electrode, dissolved in aqueous solution of sulfuric acid. Separators are composed of ion exchange materials which selectively allow transport of protons and prevent direct mixing of electrolytes at the two electrodes. The liquid electrolytes are deposited in external reservoirs \& continually circulated through the electrodes with pumps during charge and discharge, hence justifying the name, "flow battery". During discharge, the $\mathrm{V}^{+2}$ ions present at negative electrode get oxidized as a result of the electrochemical reaction and transformed into $\mathrm{V}^{+3}$ along with the discharge of an electron as expressed in Eq. 1. The released electrons take external circuit \& the protons flow through the separator to reach at the positive electrode where they combine with $\mathrm{V} \mathrm{O}_{2}{ }^{+}$through electrochemical reaction to form $\mathrm{V} \mathrm{O}^{2+}$ ion as expressed in Eq. 2. Note that water and protons are required at the positive electrode (Eq. 2) in order to maintain the stoichiometry and for balancing the charge. The reactions occuring place in the negative \& positive electrode, where $\rightarrow$ and $\leftarrow$ arrow indicates charging and discharging, respectively, are as follows:

\section{Negative Electrode}

$$
\mathrm{V}^{3+}+e^{-} \underset{\text { discharge }}{\stackrel{\text { charge }}{\rightleftharpoons}} \mathrm{V}^{2+}
$$

\section{Positive Electrode}

$$
\mathrm{VO}^{2+}+\mathrm{H}_{2} \mathrm{O} \underset{\text { discharge }}{\stackrel{\text { charge }}{\rightleftharpoons}} \mathrm{VO}_{2}^{+}+e^{-}+2 \mathrm{H}^{+}
$$




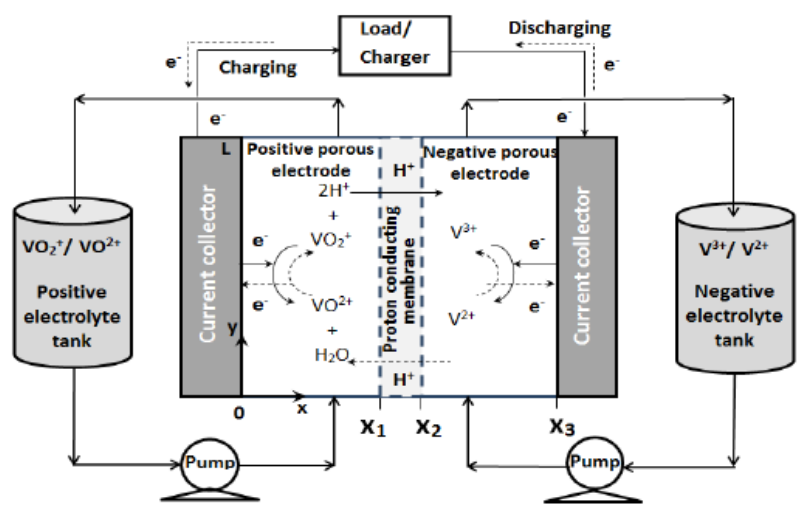

Figure 3: Main Components of Solar Chimney Power Plants.

\section{RELIABILITY OF SOLAR CHIMNEY WITH VRFB}

The abovementioned section described the working of solar chimney plants and vanadium redox flow batteries. The sustainability of a system is defined by its feasibility and efficiency. For designing an efficient solar chimney plant, minimization of various forms of energy losses and storing the unused energy is major requirement. Due to the absence of solar radiations during night or on overclouded days, the major requirement of this system is an appropriate energy storage device. The purpose of using an energy storage system is to cope up with the intermittency of the plants.

The power output of the solar chimney plant is predicted based on the turbines installed in the base of the plants [9]. Figure 4 shows the view of installed turbine.

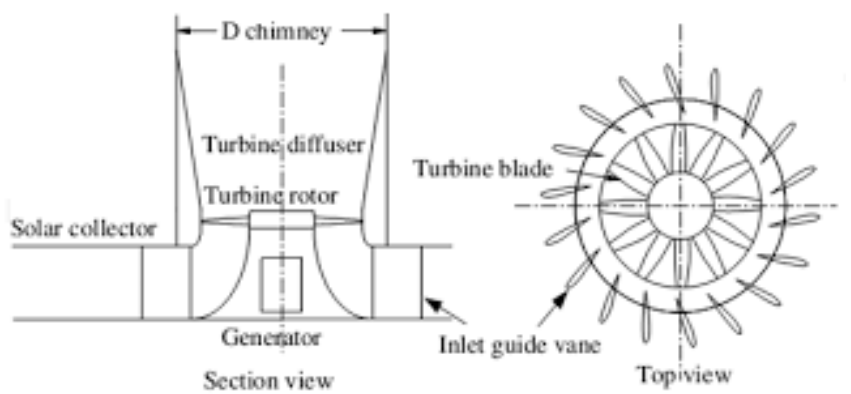

Figure 4: Solar Chimney Power Plant with Installed Turbine.

The VRFB system can be utilized here in this plant to store the excess electrical energy produced by the turbines and motors in form of chemical energy of the electrolyte. And to use this extra energy when requires, that is during night or on overclouded day.

The reliability of solar chimney with VRFB lies in the fact that installing of a VRFB system outside solar chimney does not affect the overall efficiency of the system. As it neither effect the chimney height not the radiation surface. It only stores the additional energy developed by the system. Basically, the overall efficiency of solar chimney plant is in proportion of the chimney height. The chimney effectiveness is described by the following formula:

$$
\eta_{t}=\frac{g H}{c_{p} T_{0}}
$$


Where,

$$
\begin{aligned}
& H \text { is the chimney height }[\mathrm{m}], \\
& g \text { is the gravity }[\mathrm{m} / \mathrm{s}], \\
& c_{p} \text { is the air heat capacity }[\mathrm{J} / \mathrm{kg} \cdot \mathrm{K}], \\
& T_{0} \text { is the ambient temperature }[\mathrm{K}] .
\end{aligned}
$$

So, it can be clearly stated that installing a VRFB in a solar chimney plant will not affect the gross efficiency of the system.

Also as already discussed VRFB is a very cost effective system, so by incorporating of a VRFB system outside a solar chimney plant increases the efficiency of the system by reducing the wastage of unused energy. Another important factor is that VRFB does not cause any environmental effect.

\section{CONCLUSIONS}

The purpose of designing a solar chimney plant with energy storage can be numerous. As the solar energy is renewable source of energy, so designing the system utilizing solar energy can be cost effective. Other advantage is the nonappearance of any harmful gas emission, which is like a blessing for the environment. The paper also discusses the advantages of using a vanadium redox flow battery. The all-vanadium redox flow battery (VRFB) is an emerging energy storage technologies; needed to deal with the random distribution and fluctuating nature of renewable energy resources. The success of VRFBs gives credence to its high energy efficiencies, long discharge time, and minimum waste disposal, the capability of fully getting discharged without harming the battery and its decoupled energy \& power densities

This paper begins with explaining the working principle of solar chimney and vanadium redox flow battery and then expands into providing feasibility of combining the energy storage in form of VRFB system with the solar chimney plants. We concluded that the combined system developed solves many environmental problems and it is the best pollution free method available. Despite of some of the limitations of this system, researchers have been going and soon it will be possible to see solar chimney powerplant incorporated with VRFB in the whole country.

Optimistically, this paper has provided a more profound knowledge about utilizing a energy storage device such as VRFB together with solar chimney plant. However, there are multiple physics or phenomena which are yet to be considered. So, the identified future work is to develop a mathematical model for this combine system.

\section{REFERENCES}

1. International Energy Agency. World Energy Outlook 2019. 2019.

2. Tingzhen, Ming, Liu Wei, XuGuoling, XiongYanbin, Guan Xuhu, and Pan Yuan. "Numerical simulation of the solar chimney power plant systems coupled with turbine." Renewable energy 33, no. 5 (2008): 897-905.

3. Dai, Y. J., H. B. Huang, and R. Z. Wang. "Case study of solar chimney power plants in Northwestern regions of China." Renewable Energy 28, no. 8 (2003): 1295-1304.

4. Zhou, Xinping, Jiakuan Yang, Bo Xiao, GuoxiangHou, and Fang Xing. "Analysis of chimney height for solar chimney power plant." Applied Thermal Engineering 29, no. 1 (2009): 178-185. 
5. E. Sum and M. Skyllas-Kazacos. A study of the $v(i i) / v(i i i)$ redox couple for redox flowcell applications. Journal of Power Sources, 15(2):179\{190, 1985.

6. M. Rychcik and M. Skyllas-Kazacos. Characteristics of a new all-vanadium redox flow battery. Journal of Power Sources, 22(1):59\{67, 1988.

7. Ke-Long Huang, Xiao gang Li, Su qin Liu, Ning Tan, and Li quan Chen. Researchprogress of vanadium redox ow battery for energy storage in china. Renewable Energy,33(2):186\{192, 2008.

8. Xiangkun Ma, Huamin Zhang, Chenxi Sun, Yi Zou, and Tao Zhang. An optimal strategyof electrolyte ow rate for vanadium redox ow battery. Journal of Power Sources, 203:153, 2012.

9. Pretorius, Johannes P., and Detlev G. Kröger. "Solar chimney power plant performance." (2006): 302-311.

10. Sangi, Roozbeh, MajidAmidpour, and BehzadHosseinizadeh. "Modeling and numerical simulation of solar chimney power plants." Solar energy 85, no. 5 (2011): 829-838.

11. Pretorius, J. P., and D. G. Kröger. "Critical evaluation of solar chimney power plant performance." Solar Energy 80, no. 5 (2006): 535-544.

12. Koonsrisuk, Atit, and TawitChitsomboon. "Partial geometric similarity for solar chimney power plant modeling." Solar Energy 83, no. 9 (2009): 1611-1618.

13. Khidhir, Dara Khalid, and Soorkeu A. Atrooshi. "Performance of a Solar Chimney With a Modified Collector Geometry: A Case Study From Erbil to the North of Iraq." Journal of Solar Energy Engineering 142, no. 1 (2020).

14. Koonsrisuk, Atit, and TawitChitsomboon. "Mathematical modeling of solar chimney power plants." Energy 51 (2013): 314 322.

15. Arwa Wafiq Hussein \& Mohamed Walid Ahmed, "Solar Energy: Solution to Fuel Dilemma”, IMPACT: International Journal of Research in Engineering \& Technology (IMPACT: IJRET), Vol. 2, Issue 8, pp. 99-108

16. Gajendra R. Patel, Dilip B. Patel \&Kinjal M. Paghdal, "Analysis of P\&O MPPT Algorithm for PV System “, International Journal of Electrical and Electronics Engineering (IJEEE), Vol. 5, Issue 6, pp. 1-10

17. Zatir Sara \& Benkoula Sidi Mohammed El Habib, "The Impact of Renewable Energy in Urban Planning Instruments the Case of the PDAU “, IMPACT: International Journal of Research in Engineering \& Technology (IMPACT: IJRET), Vol. 2, Issue 7, pp. 123-126

18. Monika Shekhar Gupta \& Y. P. Singh, "Climate Change and Public Awareness ", BEST: International Journal of Humanities, Arts, Medicine and Sciences (BEST: IJHAMS), Vol. 3, Issue 10, pp. 113-124

\section{AUTHORS PROFILE}

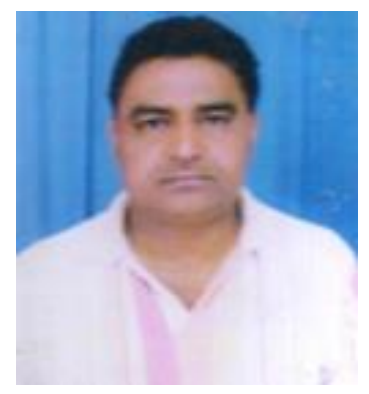


Dr. Kamal Kishore Pathak is currently working as a Lecturer (Selection Grade) at Government Polytechnic Sheikhpura (Bihar). He did his B.Sc. Engineering in Mechanical Engineering from Bihar College of Engineering, Patna in 1987. Since then he has been engaged in teaching and research. He obtained his M.Tech and Ph.D. from B.R.A. Bihar University, Muzaffarpur. He has wide exposure in the Mechanical Engineering field and has 30 years of experience in teaching engineering students. He is the life time member of Indian Society for Technical Education (ISTE) and also the author of the book "Strength of Materials (Mechanics of Solids)" ISBN: 978-8193003756, First Edition, Nexus Publication, Patna, 2017. 

